\title{
Non-fatal self-poisoning in Sri Lanka: associated triggers and motivations
}

\author{
Thilini Rajapakse ${ }^{1 *}$, Kathleen Margaret Griffiths ${ }^{2}$, Helen Christensen ${ }^{3}$ and Sue Cotton ${ }^{4}$
}

\begin{abstract}
Background: Attempted or non-fatal self-poisoning is common in Sri Lanka. To date, most preventive strategies have focused on limitation of access to toxic pesticides, which has reduced the rates of fatal self-poisoning. However the ongoing phenomenon of non-fatal self-poisoning indicates the need for exploration of alternate preventive strategies. Self-poisoning in Sri Lanka has been described as impulsive, with little premeditation, but the motivations associated with this act have not been studied in depth. This research describes the triggers and motivations associated with non-fatal self-poisoning in Sri Lanka. It is anticipated that the findings would help guide future preventive strategies.

Methods: Two studies were carried out, at Teaching Hospital Peradeniya, Sri Lanka, each using a different methodology - Study 1 consisted of qualitative semi-structured interviews, and Study 2 was a cross sectional survey. Both studies were conducted among those who had recently attempted self-poisoning, and explored associated triggers and motivations associated with the act of self-poisoning. There was no overlap between participants of the two studies.

Results: A total of 24 persons participated in the semi-structured interviews (Study 1), and 921 took part in the cross-sectional survey (Study 2). Interpersonal conflict was the most common trigger prior to the act of non-fatal self-poisoning. A mixture of motivations was associated with the act of self-poisoning, including intent to die, to escape, and difficulty tolerating distress associated with interpersonal conflict.

Conclusions: Development of interpersonal skills and interpersonal problem solving skills, particularly in adolescents and young people, emerges as a key primary preventive strategy. Further, there is value in exploring and helping people to develop more adaptive strategies to cope with emotional distress associated with interpersonal conflict. While distress tolerance and interpersonal skill training strategies used in the West may be considered, it is also important to adapt and develop strategies suited to the local cultural background. Further research is needed to develop and evaluate such strategies, and findings may have implications not only to Sri Lanka but also for other countries in South Asia.
\end{abstract}

\section{Background}

The rate of completed suicides in Sri Lanka has fallen since 1995 [1], but hospital admissions for non-fatal or attempted self-poisoning have increased in recent years $[2,3]$. Studies from Southern Sri Lanka have reported intentional self-poisoning rates of 315/100,000 [4], which is comparable to the highest attempted suicide rates reported by the WHO/EURO para-suicide study [5]. Non-fatal self-poisoning is associated with considerable economic cost to the country, as well as personal suffering

\footnotetext{
* Correspondence: gemba471@gmail.com

'Department of Psychiatry, Faculty of Medicine, University of Peradeniya, Peradeniya, Sri Lanka

Full list of author information is available at the end of the article
}

to the individual. One study estimated that the Sri Lankan government expended US $\$ 866,304$ on treatment of all self-poisonings for the year 2004 [6]. Previous research indicates that non-fatal self-poisoning in Sri Lanka is a phenomenon affecting mostly young adults of both sexes $[7,8]$, and similar to elsewhere in South Asia, it is often associated with a recent interpersonal conflict $[7,9]$. Interpersonal conflict often appears to precipitate the act [7]. However, the motives or reasons for the act, are less clearly described, and may be more difficult to delineate.

In the past, pesticides were the substances most commonly used for self-poisoning in Sri Lanka [10], and interventions to reduce suicide and self-poisoning in in this country have focused primarily on limiting access to lethal 
pesticides [1, 11]; the significant reduction in completed suicide rates since 1995 has been attributed largely to these ongoing measures [1]. Despite this reduction in completed suicides, rates of attempted or non-fatal self-poisoning have been increasing $[2,3]$. Broader strategies are now needed to address these growing rates of non-fatal self-poisoning in Sri Lanka [3]. This requires better understanding of the motives of individuals who self-harm. Thus, the objectives of this study were to identify the triggers and motivations associated with the act of non-fatal self-poisoning. Minimization of non-fatal self-poisoning is a challenging task but better understanding of the motivations underlying these acts is likely to point the way towards more specific preventive strategies.

\section{Methods}

\section{Overview of methodology}

The motives associated with the act of non-fatal selfpoisoning were explored using two studies each employing a different methodology.

In the first study (Study 1), 24 persons who had recently survived an act of self-poisoning were invited to participate in semi-structured qualitative interviews. During these interviews the motivations associated with the acts of self-poisoning were explored in depth. The findings were then used to develop a list of motivations that could be used in a larger, second study.

The second study (Study 2), was a quantitative study, carried out as part of a large cross-sectional survey of people who had survived an act of self-poisoning. Survey participants were invited to report on their motivations for their act of self-poisoning, by perusing the list of motivations derived from Study 1 and indicating whether these motivations applied to them. Further details, and gender differences in non-fatal self-poisoning in Sri Lanka, including a comparison of triggers associated with non-fatal self-poisoning in males and females, have been published previously [12].

Non-fatal self-poisoning was defined as intentional ingestion of a toxic substance or of a medication in excess of its prescribed dosage, with a non-fatal outcome.

Ethical clearance for the studies was obtained from the Faculty of Medicine, University of Peradeniya, Sri Lanka, and the Human Research Ethics Committee of the Australian National University.

\section{Participants and setting}

For both studies, the research was carried out among those who were aged 14 years or older, who had been admitted to the Toxicology Unit, Teaching Hospital Peradeniya, Sri Lanka, for medical management of a recent act of non-fatal self-poisoning. Potential participants were excluded if they could not converse in either Sinhala or English. There was no overlap in the participants for Study 1 and Study 2.
Study 1 - Semi-structured interviews of those who had recently carried out an act of non-fatal self-poisoning

Persons admitted to the toxicology unit (according to the admission register) on days when the researcher went to the unit, who met inclusion criteria, were invited to participate in the study. Those who gave written informed consent were included in the study. Thus, this was a non-random, non-consecutive sample. Recruitment took place during June-July 2011.

Each participant was interviewed in Sinhalese by the researcher, a specialist in psychiatry, in a confidential setting, within a week of the non-fatal self-poisoning act and prior to discharge from hospital. The semi-structured interview explored the following main themes: events leading up to the non-fatal self-poisoning act, and motivations underlying the act.

At the start of the interview, the participants were encouraged to describe what happened in response to open-ended questions such as "Could you tell me what happened?/What brought you into hospital?" As the interview progressed questions were designed to elicit intentions associated with the self-poisoning act (e.g., "What were your thoughts when you took the tablets/ poison?") followed by more specific questions if required to delineate the strength and nature of the suicidal ideation and other motivations underlying the act (e.g., Did you intend to die when you took the poison?).

The presence of depression or alcohol use disorders was also ascertained through a clinical interview based on ICD10 diagnostic criteria. All interviews were audiotaped, and lasted approximately 45-60 min.

\section{Scoring and categorization}

The audiotaped interviews were transcribed and translated from Sinhala into English. The transcripts were then analyzed independently by two assessors, one of whom was the first author. The second reviewer was also a doctor, with undergraduate training in psychiatry. Prior to examining the transcripts, both assessors discussed and agreed upon the methods of carrying out the analysis. During the analysis, statements about the immediate triggers and intentions associated with the self-poisoning attempt were extracted, and then itemized in a data extraction sheet, to ensure uniformity. The extracted data were then analyzed for common themes. The two assessors thereafter compared and discussed their findings, and the final categorization based on the consensus findings of both assessors.

\section{Study 2 - Exploration of motives via the cross sectional survey}

As described above, a list of motivations generated after thematic analysis of the semi-structured interviews was administered in the form of a cross-sectional survey. The participants were individuals who had been admitted 
to the Toxicology Unit of Teaching Hospital Peradeniya, for medical management of self-poisoning, over a consecutive 14-month period. Participants in the crosssectional survey were invited to peruse a list of possible motivations, and to tick one or more (if any) motivations which they thought were applicable to themselves, at the time that they attempted self-poisoning.

A total of 1334 persons met eligibility criteria to be included in the cross-sectional survey, of whom $9.1 \%$ $(n=121)$ refused consent, and $19.8 \%(n=264)$ could not be included because they either left hospital before the interviews could be conducted, or they were too physically unwell to participate. Therefore a total of 949 participants took part in the survey, of whom 921 $(97.0 \%)$ completed the questionnaire regarding motivations associated with the non-fatal self-poisoning act.

\section{Results}

\section{Study 1 - Semi-structured interviews: Self-reported triggers, and motives associated with the act of non-fatal self-poisoning}

The characteristics of the 24 participants and details of the self-poisoning act are given in Table 1 . Over $50 \%$ of participants were female, and the median age was 30 years. Pharmaceutical drugs were the most commonly ingested substance, followed by pesticide ingestion. In a majority $(>80 \%)$ the act of self-poisoning was premeditated for less than one day, and about a quarter of the participants had a previous history of suicide attempts.

Table 1 Study 1 - Semi-structured interviews: participant characteristics and details of the non-fatal self-poisoning act

\begin{tabular}{|c|c|c|}
\hline Variable & Median (min-max) & $\%(n)$ \\
\hline Female & & $54(n=13)$ \\
\hline Age years & $30(14-85)$ & \\
\hline \multicolumn{3}{|l|}{ Type of poisons ingested } \\
\hline - Pharmaceutical drug overdose & & $42(n=10)$ \\
\hline - Pesticides & & $33(n=8)$ \\
\hline - Other & & $21(n=5)$ \\
\hline $\begin{array}{l}\text { Interpersonal conflict } \\
\text { reported as acute trigger associated } \\
\text { with self-poisoning attempt }\end{array}$ & & $88(n=21)$ \\
\hline Premeditation $\leq 24 \mathrm{~h}$ & & $92(n=22)$ \\
\hline Poison obtained from home or garden & & $67(n=16)$ \\
\hline $\begin{array}{l}\text { Those with history of previous } \\
\text { suicide attempts }\end{array}$ & & $25(n=6)$ \\
\hline Depressed (ICD 10 criteria) & & $33(n=8)$ \\
\hline $\begin{array}{l}\text { Alcohol use disorder (harmful } \\
\text { use/dependency - ICD } 10 \text { criteria) }\end{array}$ & & $29(n=7)^{a}$ \\
\hline $\begin{array}{l}\text { Intoxicated at the time of } \\
\text { attempted self-poisoning }\end{array}$ & & $25(n=6)^{\mathrm{b}}$ \\
\hline
\end{tabular}

${ }^{\mathrm{a} A l l}$ males

${ }^{\mathrm{b}}$ All males who also met criteria for alcohol use disorder
At the time of interview, one-third of the participants (33 \%, n= 8) met ICD 10 diagnostic criteria for depression, and almost one third $(29 \%, n=7)$ had an alcohol use disorder (either dependency or harmful use); all of the latter were males. Content analysis of the interviews yielded interpersonal conflict as a main theme associated with the act of non-fatal self-poisoning; over $88 \%$ of participants $(n=21)$ identified a recent interpersonal conflict as an acute stressor leading up to the non-fatal self-poisoning act. In most participants, the conflict was with a close family member (parent, child, sibling or spouse) or with a partner. Only in two instances was the conflict with non-relations (neighbor, school teacher). In all participants who reported an interpersonal trigger, the act of self-poisoning occurred within $24 \mathrm{~h}$ of the interpersonal conflict. Three interviewees only did not describe interpersonal conflict as a trigger prior to the act of self-poisoning. These three participants did not describe specific reasons for attempting self-poisoning, but appeared to have carried out the act in the context of agitation associated with a relapse of psychiatric illness - two were experiencing a relapse of schizophrenia, and third had been experiencing symptoms of acute alcohol withdrawal at the time of the act.

Most interviewed participants reported more than one motive associated with the non-fatal self-poisoning act. These included reported inability to face feelings of shame, distress and emotional pain, physical pain, and anger (Fig. 1). In addition, almost two thirds $(63 \%, n=15)$ of the participants reported an intention to die at the time of ingesting the poison. The suicidal intent at the time of the act was expressed in varying ways, such as, "I just wanted to die", "At that time, I thought I wouldn't live- I would die", "I felt sad. I wanted to die, but I didn't die", and "I felt there was no point in living." In contrast the majority of participants $(n=16)$ denied having had ideas of ingesting poison or ideas of suicide prior to the interpersonal conflict. Similarly, at the time of the interview, most $(71 \%, n=17)$ reported that they were glad to have survived, while the remainder $(29 \%, n=7)$ expressed regret or ambivalence at surviving the self-poisoning attempt. A minority $(13 \%, n=3)$ expressed ongoing suicidal ideation at the time of interview.

\section{Study 2 - Cross-sectional survey: Motivations and triggers} Of the 921 participants who took part in the cross sectional survey, $45.5 \%(n=419)$ were males, and the median age was 22 years. The most common method of self-poisoning was by ingestion of a pharmaceutical drug overdose $(58.3 \%, n=537)$. Further results of the cross sectional survey have been published elsewhere [12].

More than $65 \%(69.7 \%, n=642)$ of participants in the cross-sectional survey described an interpersonal conflict as the immediate stressor prior to the act of non-fatal 


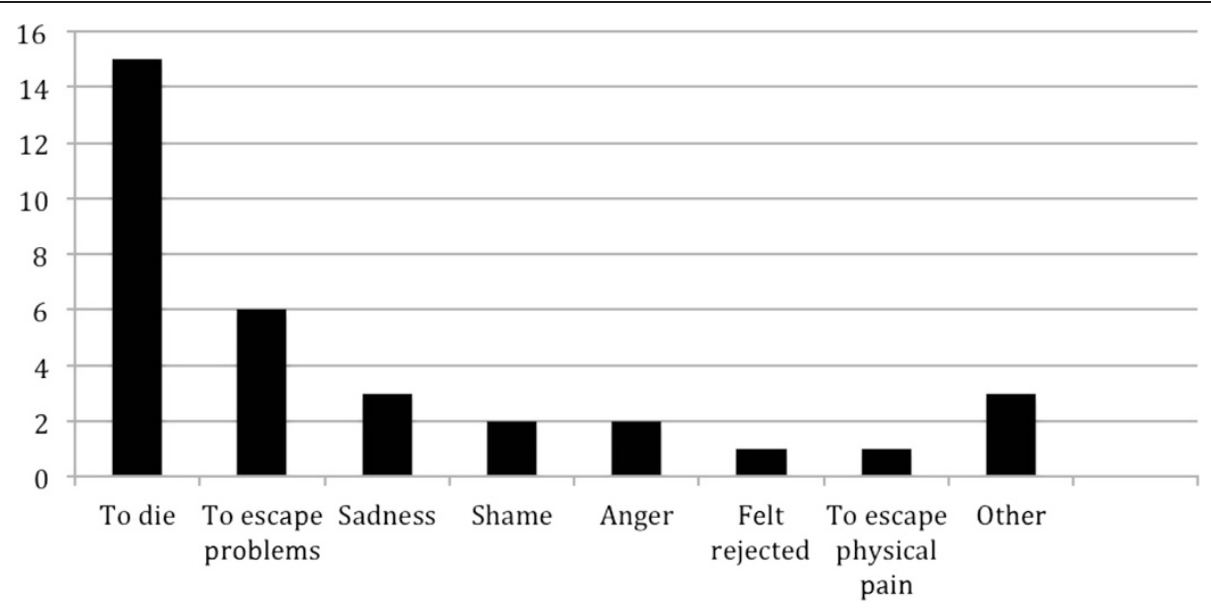

Fig. 1 Study 1 - Motivations associated with the act of non-fatal self-poisoning, as described by participants in the semi-qualitative interviews ( $n=24)$

self-poisoning (Table 2). Of these, interpersonal conflicts with a spouse, parent or regarding a romantic relationship was reported most frequently. The remaining one-third of participants described varying triggers associated with the act of non-fatal self-poisoning, such as intolerable pain symptoms (most often headaches, chest pains or limb pains) and acute stressors related to examinations. A miscellany of triggers, which could not be categorized into groups were included as 'other' $(16.8 \%, n=155)$.

Table 2 Study 2 - findings from the cross-sectional survey $(n=921)$ : Triggers associated with the non-fatal self-poisoning act and associations with intention to die

\begin{tabular}{lcc}
\hline Immediate stressors & $\%(n)$ & $\begin{array}{c}\text { Association with } \\
\text { self-reported } \\
\text { intention to die } \\
\text { P value }\end{array}$ \\
\hline Argument with spouse & $23.4(222)$ & .418 \\
Argument with parent & $17.7(168)$ & $<.001$ \\
Argument with child & $1.9(18)$ & .673 \\
Argument with other people & $9.4(89)$ & .258 \\
Argument and physical assault by husband & $1.5(14)$ & .210 \\
Conflict regarding romantic relationship & $15.4(131)$ & .003 \\
(with partner or close family members) & $3.8(35)$ & .097 \\
Severe financial difficulties & $4.1(38)$ & .008 \\
Unbearable pain symptoms & $1.4(13)$ & .936 \\
Exam stress & $0.5(5)$ & .501 \\
Insomnia or had bad dreams & $0.7(6)$ & .007 \\
Close family member recently attempted & & .365 \\
self-poisoning & $0.4(1)$ & .744 \\
Unwanted pregnancy & $16.8(155)$ \\
Other & $2.8(26)$ & .790 \\
Unable to give a reason & & \\
\hline
\end{tabular}

Participants of the cross sectional survey reported a mix of motivations associated with the act of non-fatal selfpoisoning (Table 3 ). The most commonly reported motivations or reasons were, a wish to die, a desire to escape an unbearable situation or unbearable thoughts, and an inability to control himself/herself. Those who reported an intention to die were significantly more likely to be male $\left(\chi^{2}(1)=4.45, p=.035\right)$, and aged 65 years or older $\left(\chi^{2}(2)=4.45, p=.011\right)$. When associations between selfreported intention to die and triggers precipitating the act were examined, recent conflict with parents $\left(\chi^{2}(1)=13.90, p<.001\right)$, conflict regarding a romantic relationship $\left(\chi^{2}(1)=8.89, p=.003\right)$, suffering from severe pain $\left(\chi^{2}(1)=7.07, p=.008\right)$, and having a close family member or friend having attempted self-poisoning

Table 3 Study 2 - Motivations associated with the non-fatal selfpoisoning act - findings from the cross-sectional survey $(n=921)$

\begin{tabular}{lc}
\hline Motivations associated with act & \% (n) of participants \\
\hline To die & $53.3(506)$ \\
To escape unbearable thoughts & $36.5(346)$ \\
Unable to control himself/herself & $32.5(308)$ \\
To escape an unbearable situation & $23.4(222)$ \\
To change someone's mind & $14.5(138)$ \\
To make someone sorry & $7.4(70)$ \\
Shame - felt unable to face others & $6.1(58)$ \\
To show how much I care & $2.4(23)$ \\
To show helplessness & $1.6(15)$ \\
To find out if anybody cares & $1.5(15)$ \\
To sleep for a while & $1.4(13)$ \\
To stop being a trouble to others & $1.3(12)$ \\
To get help & $0.6(6)$ \\
To get revenge & $0.6(6)$ \\
\hline
\end{tabular}


recently $\left(\chi^{2}(1)=7.36, p=.007\right)$, was significantly associated with an intention to die (Table 2).

\section{Discussion}

Most participants associated the act of non-fatal selfpoisoning with a recent interpersonal conflict. This is no surprise - previous studies from Sri Lanka $[7,13]$ and South Asia [9] have linked self-poisoning behavior to interpersonal conflicts. Interpersonal conflict could be described as a proximal trigger, closely linked to the act of non-fatal self-poisoning and the motivations associated with it. Similarly, interpersonal conflict has been commonly associated with attempted suicide in other parts of Asia, as well as in the West [14-17]. While interpersonal conflict was the most commonly reported trigger, a smaller proportion of participants also described the act of self-poisoning being associated with other triggers, such as severe financial stressors, and unbearable pain symptoms. Interestingly, severe pain symptoms were also significantly associated with a selfreported intent to die. One possible explanation is that the reported somatic pain symptoms may reflect an underlying 'hidden' depression, which contributed towards the suicidal intent [18].

Despite differences in culture and background, the motives or intentions for non-fatal self-poisoning, described by the participants in these two studies are strikingly similar to motives described in the Western literature - namely a desire to escape or a wish to die $[19,20]$.

The findings of this research provide additional insight into the processes involved. In particular, a difficulty tolerating distress associated with interpersonal conflict emerged as a key factor driving people towards selfpoisoning behaviour. For instance, participants of Study 1 described in detail the difficulty in tolerating emotional pain following interpersonal conflict, for example - "I felt very hurt" (after conflict with daughter); and "I felt very alone" (after conflict with mother-in-law and perceived lack of support from husband). A theme of acute distress, and inability to cope with this emotional state emerged clearly - one young female articulated this as, "I couldn't bear it. There was nothing else I could think of to do (other than taking poison)" (after conflict with mother). In Study 2, about one-third of participants described inability to control himself/ herself' at times of emotional distress as contributing towards this act.

Among the semi-structured interviews (Study 1), a 24year old male participant who drank poison said he had done so because he felt angry and distressed after his mother objected to his choice of girlfriend, but denied having had overt confrontation with his mother about the issue. Self-harm as a means of communicating or enacting anger has been reported by previous Sri Lankan studies [21]. The hierarchical nature of Sri Lankan society where deference to elders is encouraged, may contribute to such situations [22]. Some participants, particularly those who were older, also reported feelings of shame after interpersonal disputes, e.g., - a middle aged male participant stated: "I felt very ashamed" (after a dispute with his son about alcohol misuse). The overall emerging feature in the study was emotional distress associated with an interpersonal conflict, and reported inability to deal with that distress.

The majority of participants of the in both Study 1 and Study 2 reported an intention to die at the time of attempting self-poisoning. This finding is consistent with that of a previous Sri Lankan study reported by Hettiarachchi et al. [7]. Males and older participants were significantly more likely to report an intention to die - this is in keeping with international findings that increasing suicidal intention is associated with older age and male gender [23, 24].

In most instances, the desire to die was expressed in the context of acute distress associated with interpersonal conflict. In keeping with this, by time of interview (within one week of the act of non-fatal self-poisoning), the majority of participants of the semi-structured interviews reported no current suicidal ideation, and was glad to have survived. Likewise, the duration of premeditation associated with the act of non-fatal self-poisoning was short. Most of the acts of non-fatal self-poisoning occurred within $24 \mathrm{~h}$ of the interpersonal conflict, similar to previous Sri Lankan studies $[25,26]$.

While the desire to escape, or to die, emerge as key themes, overall motivations often appeared mixed and complex. Although not the most commonly reported motivations, many participants in the cross-sectional survey subscribed to motives such as to change someone's mind, to make someone sorry, to show how much I care, to show helplessness - which appear to be acts of communication with a significant other. Further, the distressing emotions described by the participants, such as sadness, anger, or shame are all likely to have contributed towards self-poisoning behaviour.

Notably, none of the participants in either study identified depression as being associated with the non-fatal self-poisoning act. This was despite the fact that about one third of the interview participants (Study 1) were clinically depressed at interview. This is in contrast to findings from the West [27], where survivors have described their self-harm attempts as being associated with depression. This difference in the way persons interpret their experiences may be partly due to the fact that in Sri Lanka, as in other South Asian cultures, the symptoms of depression are often not conceptualized as a disorder [28], and indeed there is no colloquial term for depression in the Sinhala language. 


\section{Limitations}

The semi-structured interviews were limited by the small sample size, but a strength of the study was the structured, detailed nature of the interviews, and that relevant information was extracted systematically by use of audio-taping, transcribing, data extraction sheets and dual coding of the intervention strategies. Although the data was assessed by two raters, inter-rater reliability was not formally assessed which is a limitation. The assessors discussed and agreed upon the method of assessment prior to analysis, but there was no formal training prior to the analysis, which also may have been a limitation. However, the qualitative nature of this study added depth and detail to the information gathered through the quantitative survey. The retrospective recall of events by participants in both the interviews and cross-sectional survey is also a limitation, since this method may have led to a recall bias, although efforts were made to minimize this by conducting the interviews within one week of the non-fatal self-poisoning act. Further, due to restriction of numbers, it was not possible to undertake further analysis of possible associations between different types of triggers and motivations, and this is a further limitation of the study.

\section{Conclusions}

Two main findings emerge from the two studies reported here: (i) interpersonal conflict is a proximal trigger associated with non-fatal self-poisoning, in most instances; and (ii) a mixture of motivations is associated with the act, including a desire to die, a desire to escape, and difficulty tolerating distressing emotion associated with interpersonal conflict. The intention to die, although commonly reported, appears short lived and associated with the emotional distress.

These findings have important implications for the prevention of self-poisoning in Sri Lanka. Development of interpersonal skills and interpersonal problem solving skills, particularly in adolescents and young people, emerges as a key preventive strategy. For example, interventions such as grass-root level community and youth programs to help people develop ways of dealing with interpersonal stress warrant further exploration, and such programs have shown promise internationally $[29,30]$. However it is also important to tailor these programs to suit the local sociocultural framework. In particularly, factors such as the collectivistic rather than individualistic nature of society in Sri Lanka, and the hierarchical framework where overt confrontation is discouraged - which in itself might be contributing towards the interpersonal stress - should be taken into account when conceptualizing such programs [31]. Another worthwhile avenue to explore is whether the internet could be used to engage young people - social media such as Facebook is now popular among urban Sri Lankan youth, and online interventions may provide a way of delivering training in interpersonal skills. Online interventions in the West have demonstrated efficacy in reducing symptoms of depression [32].

Difficulty in coping with acute distress related to interpersonal conflict, was another key aspect that emerged from this study. While distress tolerance strategies have been explored in the West [33], this is a little researched area in Sri Lanka, and indeed much of South Asia. There is value in exploring and helping people to develop more adaptive strategies to cope with emotional distress associated with interpersonal conflict, and once again, it is important to adapt and develop strategies suited to the local cultural background. Development of such programs requires further research and evaluation, and findings may have implications not only to Sri Lanka but also for other countries in South Asia.

\section{Competing interests}

The authors declare the have no competing interests.

\section{Authors' contributions}

$\mathrm{TR}, \mathrm{KG}$ and $\mathrm{HC}$ were involved in the conceptualization and organization of the study. TR conducted the interviews and was involved in the analysis of the interviews. TR and SC were involved in statistical analysis. All authors have seen and approved the final version submitted for publication.

\section{Acknowledgements}

The authors wish to sincerely thank the staff of the toxicology unit, Teaching Hospital Peradeniya, Sri Lanka and also the South Asian Clinical Research Collaboration (SACTRC) for their support and help during this study.

\section{Author details}

'Department of Psychiatry, Faculty of Medicine, University of Peradeniya, Peradeniya, Sri Lanka. ${ }^{2}$ Centre for Mental Health Research, The Australian National University, Building 63, Canberra ACT 0200, Australia. ${ }^{3}$ Black Dog Institute, University of New South Wales, Hospital Road, Randwich, NSW 2013, Australia. ${ }^{4}$ Centre for Youth Mental Health, University of Melbourne, 35 , Poplar Road, Parkville, VIC 3052, Australia.

Received: 4 April 2015 Accepted: 20 October 2015

Published online: 24 November 2015

\section{References}

1. Gunnell D, Fernando R, Hewagama M, Priyangika WDD, Konradsen F, Eddleston M. The impact of pesticide regulations on suicide in Sri Lanka. Int J Epidemiol. 2007;36(6):1235-42.

2. Senadheera C, Marecek J, Hewage C, Wijayasiri WAA. A hospital-based study on trends in deliberate self-harm in children and adolescents. Ceylon Med J. 2010;55(2):67-8

3. Hanwella R, Senanayake SM, De Silva V. Geographical variation in admissions due to poisoning in Sri Lanka: a time series analysis. Ceylon Med J. 2012:57(4):152-8.

4. Manuel C, Gunnell DJ, van der Hoek W, Dawson A, Wijeratne IK, Konradsen F. Self-poisoning in rural Sri Lanka: small-area variations in incidence. BMC Public Health. 2008;8:26

5. Platt S, Bille Brahe U, Kerkhof A, Schmidtke A, Bjerke T, Crepet P, et al. Parasiticide in Europe: the WHO/EURO multicentre study on parasuicide. I. Introduction and preliminary analysis for 1989. Acta Psychiatr Scand. 1992:85:97-104.

6. Wickramasinghe K. Cost to government health-care services of treating acute self-poisonings in a rural district in Sri Lanka. Bull World Health Org. 2009;87(3):180-5.

7. Hettiarachchi J, Kodituwakku GC. Self poisoning in Sri Lanka: motivational aspects. Int J Soc Psychiatry. 1989;35(2):204-8.

8. Jeyaratnam J, de Alwis Seneviratne RS, Copplestone JF. Survey of pesticide poisoning in Sri Lanka. Bull World Health Organ. 1982;60(4):615-9. 
9. Parkar SR, Dawani V, Weiss MG. Clinical diagnostic and sociocultural dimensions of deliberate self-harm in Mumbai. India Suicide Life Threat Behav. 2006;36(2):223-38.

10. van der Hoek W, Flemming K. Analysis of 8000 hospital admissions for acute poisoning in a rural area of Sri Lanka. Clin Toxicol. 2006;44(3):225-31.

11. Hawton K, Ratnayeke L, Simkin S, Harriss L, Scott V. Evaluation of acceptability and use of lockable storage devices for pesticides in Sri Lanka that might assist in prevention of self-poisoning. BMC Public Health. 2009;9:69.

12. Rajapakse T, Griffiths KM, Christensen H, Cotton S. A comparison of non-fatal self-poisoning among males and females, in Sri Lanka. BMC Psychiatry. 2014;14(1):221.

13. Chandrasena R. A Transcultural Evaluation of "Self Poisoning" in Sri Lanka. Int J Soc Psychiatry. 1981;27(2):119-23.

14. Thanh HTT, Jiang GX, Van TN, Minh DPT, Rosling H, Wasserman D. Attempted suicide in Hanoi. Vietnam Soc Psychiatr Psychiatr Epidemiol. 2005;40(1):64-71.

15. Brent DA. Risk factors for adolescent suicide and suicidal behavior: mental and substance abuse disorders, family environmental factors, and life stress. Suicide Life Threat Behav. 1995;25(s1):52-63.

16. Beautrais $A L$, Joyce $P R$, Mulder RT. Precipitating factors and life events in serious suicide attempts among youths aged 13 through 24 years. J Am Acad Child Adolesc Psychiatry. 1997;36(11):1543-51.

17. Bancroft J, Skrimshire A, Casson J, Harvard-Watts O, Reynolds F. People who deliberately poison or injure themselves: their problems and their contacts with helping agencies. Psychol Med. 1977;7(2):289-303.

18. Simon GE, VonKorff M, Piccinelli M, Fullerton C, Ormel J. An international study of the relation between somatic symptoms and depression. N Engl J Med. 1999;341(18):1329-35.

19. McAuliffe C, Arensman E, Keeley HS, Corcoran P, Fitzgerald AP. Motives and suicide intent underlying hospital treated deliberate self-harm and their association with repetition. Suicide Life Threat Behav. 2007;37(4):397-408.

20. Bancroft JH, Skrimshire AM, Simkin S. The reasons people give for taking overdoses. British J Psychiatry. 1976;128(6):538-48.

21. Marecek J, Senadheera C. 'I drank it to put an end to me': Narrating girls' suicide and self-harm in Sri Lanka. Contribut Indian Sociol. 2012;46(1-2):53-82.

22. Marecek J. Culture, gender, and suicidal behavior in Sri Lanka. Suicide Life Threat Behav. 1998;28(1):69-81.

23. Merrill J, Owens J. Age and attempted suicide. Acta Psychiatr Scand. 1990;82(5):385-8.

24. Suominen $\mathrm{K}$, Isometsä E, Haukka J, Lönnqvist J. Substance use and male gender as risk factors for deaths and suicide. Soc Psychiatr Psychiatr Epidemiol. 2004;39(9):720-4.

25. De Silva $V$, Ratnayake A. Increased use of medicinal drugs in self-harm in urban areas in Sri Lanka. Arch Suicide Res. 2008;12(4):366-9.

26. Eddleston M, Karunaratne A, Weerakoon M, Kumarasinghe S, Rajapakshe M, Rezvi Sheriff $M H$, et al. Choice of poison for intentional self-poisoning in rural Sri Lanka. Clin Toxicol. 2006;44(3):283-6.

27. Sinclair J. Understanding resolution of deliberate self harm: qualitative interview study of patients' experiences. BMJ. 2005;330(7500):1112-0.

28. Kinzie JD, Manson SM, Vinh D, Tolan N, Anh B, Pho T. Development and validation of a Vietnamese-language depression rating scale. Am J Psych. 1982;139(10):1276.

29. Mann JJ, Apter A, Bertolote J, Beautrais A, Currier D, Haas A, et al. Suicide prevention strategies: a systematic review. JAMA. 2005;294(16):2064-74.

30. McLeavey BC, Daly RJ, Ludgate JW, Murray CM. Interpersonal problemsolving skills training in the treatment of self-poisoning patients. Suicide Life Threat Behav. 1994;24(4):382-94.

31. Niles FS. Individualism-collectivism revisited. Cross-Cultural Res. 1998:32(4):315-41.

32. Griffiths KM, Farrer $L$, Christensen $H$. The efficacy of internet interventions for depression and anxiety disorders: a review of randomised controlled trials. Med J Aust. 2010;192(11 Suppl):S4-S11.

33. Linehan MM, Tutek DA, Heard HL. Interpersonal outcome of cognitive behavioral treatment for chronically suicidal borderline patients. Am J Psych. 1994;151(12):1771-6

\section{Submit your next manuscript to BioMed Central and take full advantage of:}

- Convenient online submission

- Thorough peer review

- No space constraints or color figure charges

- Immediate publication on acceptance

- Inclusion in PubMed, CAS, Scopus and Google Scholar

- Research which is freely available for redistribution

Submit your manuscript at www.biomedcentral.com/submit 